Beyond Philology No. 17/4, 2020

ISSN 1732-1220, eISSN 2451-1498

https://doi.org/10.26881/bp.2020.4.04

\title{
Disfluencies in sight translation vis-à-vis domi- nating text function: A pilot study based on English-Polish sight translation performed by professional interpreters
}

\author{
PAULA GORSZCZYŃSKA
}

Received 30.11.2020, received in revised form 28.12.2020,

accepted 29.12.2020

\begin{abstract}
The aim of the paper is to provide an account of a pilot study whose primary intention was to classify and analyse disfluencies that recur in sight translations performed by professional interpreters. For this purpose, Gósy's disfluency taxonomy $(2004,2007)$ was modified and applied to ten professional translations of three source texts (STs), the latter representing three text functions reflecting Christina Nord's interpretation of Katherine Reiss' classification (Reiss 1989 in Nord 1997), namely informative, expressive and operative one. An attempt was also made to trace any interdependencies of disfluency occurrence and ST dominating function.
\end{abstract}

\section{Keywords}

speech disfluencies, hesitations, sight translation, text type, text function 


\title{
Zakłócenia płynności w tłumaczeniu a vista a dominująca funkcja tekstu. Badanie pilotażowe w oparciu o tłumaczenie a vista w parze językowej angielski-polski wykonane przez profesjonalnych tłumaczy ustnych
}

\begin{abstract}
Abstrakt
Celem artykułu jest przybliżenie czytelnikowi badania pilotażowego, w ramach którego przeanalizowano i sklasyfikowano zakłócenia płynności dyskursu w tłumaczeniu à vista wykonanym przez profesjonalnych tłumaczy ustnych. By umożliwić sklasyfikowanie zakłóceń, poproszono 10 profesjonalnych tłumaczy o przetłumaczenie à vista fragmentów trzech tekstów, które odzwierciedlały trzy typy dominujących funkcji testu w rozumieniu Nord (1997) na podstawie Reiss (1989), czyli informacyjna, ekspresyjna i operatywną. Podjęto również próbę powiazania wystapień poszczególnych typów zakłóceń z dominująca funkcją teksu, którego dotyczyły.
\end{abstract}

\section{Słowa kluczowe}

zakłócenia płynności dyskursu, zawahania, zająknięcia, tłumaczenie a vista, typ tekstu, funkcja tekstu

\section{Introduction}

As proven by researchers, fluency is one of the factors with the strongest impact on the evaluation of interpreter' performance, reliability and overall quality of interpretation (Collados Aís et al. 2007: 218, García Becerra 2007: 314). As such it has been studied thoroughly and approached from many different angles. Scholars propose definitions of fluency that are characterised by a high degree of overlap (inter alia: Chambers 1997, Götz 2013, Pradas Macías 2006, Rennert 2010). Rennert, for example, describes fluency as "a prosodic feature of speech that can be viewed as a function of a number of temporal variables. It is the 
complex interaction of pauses, audible breathing, hesitations, vowel and consonant lengthening, false starts, repairs, repetitions and speech rate [...]" (2010: 104). A more general understanding of the term is that of an uninterrupted natural and proficient flow of speech (Chambers 1997). Disfluency ${ }^{1}$ would, therefore, be marked by any breach of fluency thus understood, i. e. an occurrence of any of the variables mentioned.

Cecot (2001: 70-71) developed a handy classification of different shades of "non-fluencies, i.e. fluency interruptions". The umbrella category of "non-fluencies" also encompasses "disfluencies", among which we will find the features whose temporal interplay result in an output of a varying degree of fluency (Rennert 2010: 104). These are: filled pauses, glottal clicks, audible breaths, vowel and consonant lengthening, parenthetical sentences, and utterance interruptions, including repeats, restructuring and false starts.

A similar approach is adopted by Tissi in her taxonomy (2000: 122), which comprises silent pauses and disfluencies further subdivided into subcategories: "[...] silent pauses (the two subcategories being grammatical and/or communicative pause and non-grammatical pauses) and disfluencies. The latter include filled pauses (further broken down into vocalized hesitations and vowel and consonant lengthening) and interruptions (further broken down into repeats, restructuring and false starts)".

Gósy (2007: 93 in Bakti 2009: 5-6) approaches speech disfluencies as "phenomena that interrupt the flow of speech and do not add propositional content to an utterance". She divides them into two major categories: (a) disfluencies rooted in uncertainty and (b) errors or error-type disfluencies (ETDs). Among the main sub categories of uncertainty-related speech disfluencies there are: hesitations, fillers, repetition, restarts, leng-

\footnotetext{
${ }^{1}$ Magno Caldognetto et al. (1982) offers one of the classical taxonomies of disfluencies. The terms 'disfluency', 'non-fluency', 'influency', 'fluency disruption' overlap to a varying degree across different studies. Throughout this paper, 'disfluency' should be used as an umbrella term. The other terms will be used mainly in relation to other scholarly contributions referred to in this text.
} 
thening and pauses within the word. The error-type disfluencies include: Freudian slips, grammatical errors, contamination, false word activation, "tip of the tongue" (TOT), change, ordering pro-blems and slips.

A majority of the studies alluded to thus far concern the output of simultaneous or consecutive interpreting (SI and CI, respectively), either applying or generating varying classifications of disfluencies. A selection of these classifications is presented in section 2 below. A question arises whether classifications which are meant to describe the output of SI or CI are also applicable to sight translation ( $\mathrm{SiT}^{2}$ ). In other words, we will try to learn whether similar types of disfluencies as those that occur in simultaneous translation can also be found in sight translation. The notion of SiT is to be understood here as proposed by, among others, Angelelli (1999: 27), i.e. as "[...] an oral translation of a written text that should sound as if the interpreter were merely reading a document written in the target language", and as the outcome of the process.

There has been dispute among translation scholars as to whether this signifier should or should not be viewed as denoting the same scope of actions and/or results as those of sight interpreting. Franz Pöchhacker, for instance, emphasises the importance of the temporal factor and claims that "In sight translation, the interpreter's target-text production is simultaneous not with the delivery of the source text but with the interpreter's real-time (visual) reception of the written source text." (Pöchhacker 2016: 20). Pointing at the common misuse of the term, the scholar contrasts SiT with sight interpreting, which he considers to be "a variant of the simultaneous mode [...] practiced in real time for immediate use by an audience" (Pöchhacker 2016: 20).

Reinart (2014) advocates classifying the act of rendering orally a translation of a written content as a hybrid communicative act. She believes that assigning this borderline case to the

\footnotetext{
$2 \mathrm{SiT}$ is to be understood here as sight translation. This symbol has been chosen instead of the simpler ST, which denotes ST.
} 
domain of either translation or interpreting tends to be based on relative criteria. Lambert (2004) also appreciates the hybrid nature of the process, believing it to be a particular kind of both written translation (processing visual information) and interpreting (oral processing of information). Still, she chooses to call it sight translation, and preserves the term 'sight interpreting' for the process that is also called 'simultaneous-with-text interpreting'. In this mode, in which a booth interpreter can simultaneously hear the speaker and read the transcript of the speech, both the auditory and written input is present. However, it is what the interpreter hears that is subject to the actual simultaneous oral processing.

The dichotomy between sight translation and sight interpreting, or lack thereof, also permeates the Translation Studies discourse concerning other language pairs. For instance, the scholars working with German as one of the languages in the pair involved in translation use a number of terms to denote a target language rendition of a written source text (ST). These include, among other labels, Vom-Blatt-Dolmetschen, Blattdolmetschen (interpreting from a sheet of paper, sheet-of-paper interpreting), Blatt-Übersetzen (sheet-of-paper translation), Stegreifübersetzen (extemporaneous translation), Stegreiftranslation (extemporaneous translation), Spontanübersetzung (spontaneous translation) and Diktieren einer Rohübersetzung (dictating a rough version of a translation) (Parkin 2012: 21-24). The naming options vary and depend on factors such as presence or absence of a spoken ST alongside the written one, a temporal constraint or lack thereof, circumstances in which SiT is performed and used, the form in which the written ST was given to the translator, the latter's familiarity with the ST, to mention just a few.

As we can see, sight translation can be applied in situations that do not involve the audience (e.g. the translator dictates his rough SiT version and sends the file to the client to give them a general sense of what the source document contains). However, it can also be interwoven in conference or business interpreting contexts. Here, for instance, the speaker gives the translator a written text for them to render it into the target language 
in front of the participants of the meeting. Pöchhacker argues that if there is no time pressure of the in-front-of-the-audience performance, the translator is likely to freely introduce corrections, reviewing the output, much as in the written translation process, in which case "sight interpreting will shade into the consecutive mode or even come to resemble 'oral translation' [...]" (Pöchhacker 2004: 19; 2016: 20). Drawing from these observations, we shall attempt to analyse the nature of some of these revisions in SiT.

Another objective of the study that this article aims to present is to capture any interdependencies between performance disfluencies and the dominating type of text that is sight translated. Following Reiss (1989), Nord (1997) adopts a classification of dominating textual functions into informative, expressive and operative. The informative function consists in communicating facts about real world objects and phenomena to the reader without distracting him or her with elaborate linguistic or stylistic forms. The focus of expressive texts is more on the aesthetic factor, which co-creates the message of the text by means of stylistic choices adopted by the author. In operative texts the extralinguistic effect is superior to both content and form. In other words, the text calls the reader to act or refrain from acting in a particular way (Nord 1997: 37-38). Identifying which disfluencies tend to recur in sight translation of texts with a given dominant function may prove to be an important step towards reducing their rate. This could be achieved via sight translation training targeted at particular text types, designing of which, however, exceeds the scope of the present study.

Having sketched the rationale behind this article, its author will first present an overview of research on speech disfluencies in simultaneous and consecutive interpreting (Section 2.1). Section 2.2 will provide an account of selected studies pertaining to speech disfluencies in sight translation. Section 3 will contain a description of a pilot study carried out within ongoing research on SiT disfluencies, and will be followed by a presentation of results and their interpretation (Section 4) and conclusions (Section 5). 


\section{Speech disfluencies in oral translation - research overview}

There has been a multitude of approaches to perceptive studies of the impact of disfluencies on translation comprehensibility and on the general rating of the translation quality by its recipients. Different scholars studied fluency as either a single complex phenomenon, focused on its subfeatures in isolation, related it to speech aspects such as prosody or treated it as one of the prosodic features. Even though some studies have been replicated, there seems to be no consensus as to which factors, or a combination thereof, have the most detrimental impact on the final assessment of the translation by its users. This section constitutes a brief review of a number of fluency studies concerning simultaneous interpreting and consecutive interpreting as those setting the stage (subsection 2.1), as well as recent studies devoted to exploring sight translation from the perspective of the cognitive challenges it poses (subsection 2.2).

\subsection{Disfluencies in simultaneous interpreting}

Since we adopted Rennert's definition of fluency as the one we shall relate to in this paper, let us glance at one of her studies first. The scholar studies a correlation between interpretation fluency and the perception of its intelligibility and interpreter's performance (2010: 111-112). The study exposed the respondents, business students with a considerable understanding of marketing, to one of the two versions of a professional SI rendition from English to German of a single source lecture on innovative marketing. The versions varied in terms of their fluency, one being manipulated so as to enhance and the other so as to lower its fluency level. This is how Rennert describes the modification introduced to the recording:

One copy of the selected base version was then manipulated for increased fluency by removing hesitations, false starts and audible breathing that had a negative impact on fluency, and shortening or 
removing pauses in non-syntactic positions, while at the same time adding pauses and calm audible breathing to syntactic positions. A second copy was turned into the non-fluent version by adding pauses, hesitations and audible breathing to non-syntactic positions, lengthening existing pauses in non-syntactic positions and adding false starts, lengthened sounds and repairs.

The interventions Rennert introduced to render one of the recordings less fluent mirror the disfluencies typical of spontaneous speech, even one made with an external input, as is the case with interpreting. A rudimentary disfluency list based on Rennert's would then include: excessively frequent or excessively long pauses, hesitations, audible breathing in non-syntactic positions, false starts ("created by interrupting a sentence and beginning a new one without completing or correcting the previous sentence" [Rennert 2010: 104]), lengthened sounds and repairs ("corrections of errors in pronunciation, grammar, structure, content or style" [Rennert 2010: 104]).

As a second stage of Rennert's study, a survey was used in which the study participants answered comprehension questions and subjectively rated the fluency of the rendition they heard. Thus fluency was singled out as a quality factor, which might impact the users' overall assessment of an SI performance. The results "suggest that there is a link between perceived fluency and perception of the interpreter's accuracy, confirming previous studies that suggested that lower fluency may impact negatively on the perceived quality of an interpretation" (Rennert 2010: 112).

In her experiment, having applied her own disfluency classification, Cecot (2001) detected, measured and compared the non-fluencies occurrence in STs and TTs to gain insight into the possible causes of professional interpreters' hesitating and pausing. She invited 11 professional interpreters to perform a simultaneous interpretation from English (B) into Italian (A) of two texts delivered at two different speech rates. Additionally, the interpreters' performance self-assessment was confronted with the objective data concerning pause occurrence, duration 
and function versus ST speech rate. Interestingly, the majority of the subjects proved unaware of the hesitation pauses they had made. Women interpreters tended to use fewer unfilled pauses, while men spoke more slowly and paused more. Since women tended to speak faster, the disfluency rate in their output was higher. On the other hand, there was a lower total number of disfluencies in the TTs produced simultaneously to the ST delivered at a higher pace. With a lower ST pace, interpreters have more time for planning (Cecot 2001: 78), a factor bringing this situation closer to most SiT-related situations, even if SI is still far more speaker-dependent than the interpreter-paced SiT. The dominating pauses identified in the study were segmentation ones, followed by hesitation pauses (Cecot 2001: 80).

Pradas Macias $(2006,2007)$ also focused on pauses, silent pauses in particular, which she tested as subparameters of fluency. To study the perception of German to Spanish SI, she manipulated the input ST interpretation by inserting a varying number of pauses into the original rendition thus creating two additional versions enriched by 13 and 20 added pauses. Each version was then subject to survey-based rating by one of three sub-groups of law professors, in which they assessed fluency as one of 14 translation quality parameters. In her conclusions, the scholar emphasised the link between pauses, intonation and speech continuity, and suggested it was legitimate to use groups of parameters rather than isolated one for quality evaluation (Pradas Macías 2006: 39). The results appear to suggest that a higher number of silent pauses in an interpreter's output is likely to have a negative impact on users' assessment of fluency, which is acceptable for the users as long as it does not impact the comprehensibility of the message rendered. At the same time, once detected by the users, silent pauses are likely to influence negatively their assessment of factors such as fluency, intonation or impression of interpreter's professionalism. In an extended version of the 2006 study, Pradas Macias (2007) broadened the scope of potentially relevant disfluencies by manipulating the experimental material not only by inserting silent pauses but also filled ones, false starts and reformulations. 
Again, the impact of the manipulation was clearly negative in relation to not only the perception of fluency but also general quality and intonation (Pradas Macias 2007: 66-67).

Bakti (2009) presents the results of two studies whose objectives were to identify the most common error type disfluencies (ETDs) in the simultaneous interpreting output of trainee and professional interpreters and to investigate the origins of these disfluencies in the workings of the speech production system. Bakti classifies SI as speech production in ambient noise and, following Gósy (2007: 102), expects restarts, lengthenings and repeats to constitute a substantial share of all the disfluencies that the subjects are likely to produce. These disfluencies, which Gósy herself classifies as errors rooted in uncertainty, are likely to accompany changed pausing patterns among other differences between no-noise and in-noise speech production. They may result from the necessity to divide attention in noisy environments. As Gósy puts it: "the speakers restart the words and repeat them when there is a mismatch between planning and execution in order to save their planning mechanism from intruding (disturbing) noise" (Gósy 2007: 102). In Bakti's study seven trainee interpreters interpreted simultaneously a 12-minute read-out speech from English (B) to Hungarian (A). The errors found in the transcriptions of the recorded interpretations were categorised following Gósy's taxonomy of disfluencies (2004). The procedure was then repeated with three professional interpreters, the only difference being that they worked from a recording. It is not clear, however, whether it was an audio or video recording, which makes it impossible to trace back potential impact of the ST form (audio vs. audio-visual) onto the practicing interpreters' output. The results showed that most disfluencies in the output of both groups of subjects were in fact restarts and grammatical errors, followed by false word activation, and that their occurrence is related to "morphological and syntactic planning and co-ordination between lexical access and articulatory planning" (Bakti 2009: 13). As Bakti did not take into account the occurrence of lengthenings or repeats in her research design, it cannot be confirmed whether their occur- 
rence in her subjects' output would corroborate Gósy's and Tissi's findings on them dominating the disfluency or slip rates in SI (Gósy 2007: 102; Tissi 2000: 120-122).

SI prosodic features and their impact on the listeners' assessment of interpretation comprehensibility, its fluency and accuracy were also studied by Christodoulides and Lenglet (2014). The scholars exposed 47 experts and 40 non-experts to a 20minute lecture on an investment strategy, which was delivered in German and sight interpreted into French by a professional interpreter working into his mother tongue. Each of the subject heard either the recording of the actual interpretation or a recording of the same interpretation in the form of a transcript read out by the same interpreter. The subjects were then asked to answer a set of comprehension and rating questions. The analysis of prosodic features of both input materials juxtaposed with the subjects' answers showed that in as much as the prosody does impact the perception of the fluency of interpreter's output and indirectly that of its accuracy, this impact is weaker in the case of expert listeners, who approach the text with a greater contextual knowledge. In terms of average silent pause length, it proved greater in SI as compared to the texts read aloud, while as regards audible disfluencies, 272 pauses were found in SI with only 8 in the read-out text. Whereas there were almost no other disfluencies in the read-out text, the SI output displayed false starts, repetitions and deletions (in order of frequency) (Christodoulides and Lenglet 2014: 1004).

\subsection{Speech disfluencies in sight translation}

The studies on speech fluency in sight translation have been notably less numerous than those exploring fluency in SI. It is only the last few years that have seen the revival of scholarly interest in this topic, which was sparked in 2010 when Shreve, Lacruz and Angelone published a chapter based on an experiment comparing the cognitive load of a number of SiT aspects to that accompanying written translation. Eye-tracking was used to detect any performance disruptions and correlate them 
with the manipulated input. The study was followed up in 2011 when a report was published on SiT performance analysis from a cognitive perspective (Shreve, Lacruz and Angelone 2011). The authors hypothesised that the more syntactically complex a segment of a ST is, the greater the difficulty and disruption of comprehension, transfer and production. They also predicted that the disruption can be measured on the basis of an increased number of TT errors (speech disfluencies included, following Gósy's definition [2004]) and with the use of eye tracking parameters reflecting increased cognitive effort. Eleven EnglishSpanish translation programme students were asked to, respectively, translate in writing and sight translate two paragraphs of general Spanish texts (on tourism), each set containing one noncomplex paragraph and the other which had been manipulated syntactically so as to contain a complex sentence. Meticulous transcription and annotated protocols were applied and the findings were triangulated with the data from eye tracking. The authors claim that the disfluencies of speech that were analysed within the study, i.e. unfilled pauses, filled pauses, repetitions and repairs/revisions, are indicative of the cognitive load related to visual interference. They also believe that the workings of interpreters' minds can be accessed by means of analysing the ways and strategies they use when faced with challenges on the level of lexis ${ }^{3}$ or syntax.

Bakti (2017) offers a close-up approach to speech disfluencies in SiT by exploring explicitation patterns in SiT as compared to those in SI. She expects that apart from the cohesive shifts typical of SI, SiT output is likely to abound in the shifts whose function is to add or explain rather than enhance target text (TT) cohesion, explicitation being one of such non-cohesive shifts. In the study, ten MA level translation and interpreting students with Hungarian as their A language and English as they $\mathrm{B}$ or $\mathrm{C}$ language (three and seven students respectively) were asked to talk about English as a lingua franca, then

3 The lexical level, next to visual interference, was singled out by Mikkelson (1995) as unique to SiT due to the fact that constant presence of written input pushes the interpreter into focusing on particular words. 
perform a SiT and a consecutive interpretation on the same topic, and finally fill in a questionnaire on their background, language competence and the tasks performed. Transcripts of the SiT task were then analysed in search for explicitations as classified by Gumul (2006).

The results show that interpreters performing oral translations of written input tend to produce output enriched with explicitations whose function is different from the one they serve in SI. While explicitation shifts detected in SI are usually those strengthening text cohesion, the ones in SiT tend to add new pieces of information to the ST content (Bakti 2017). The main types of explicitation spotted in the TTs were, in order of frequency, replacing nominalizations with verb phrases, adding modifiers and qualifiers, adding explanatory remarks and adding connectives. As all these interventions tend to increase the number of words in the TT, that being particularly true of the explanatory shifts, it appears worthwhile to investigate the latter as potentially disruptive to the fluency of SiT.

This overview of interpreting- and SiT-related fluency studies reveals a variety of approaches and methodologies applied by scholars often with the intention of gaining insight into the working of the interpreter's cognitive processes and thus understanding the intricacies of ST decoding and target speech production. Although SI and SiT do differ in terms of the mode and nature of input, oral and written respectively, they both produce spoken output. Since disfluencies occur in both these translation modes but appear to have been understudied in the case of SiT, it might be interesting to explore SiT through the lens of the disfluency categories elicited and analysed by the scholars whose work has been referred to in sections 2.1 and 2.2 of the present article.

\section{Pilot study on disfluencies in English to Polish SiT versus dominating text function}

In this section of the paper a pilot study will be presented, whose main objective was to establish, against the background of 
speech disfluencies proven to recur in SI, which categories of disfluencies also appear in sight translation. It appears justified to assume that the types of disfluencies which occur in SI as a result of the constraints of working in noise and under considerable time pressure imposed by the speaker's speech rate will be rare if not non-existent in most SiT products. Given that the input - the written ST - is readily available to the interpreter throughout the translation process,${ }^{4}$ it seems likely that there is more time for speech planning and thus disfluencies like restarts and repetitions should not be as pronounced. The text availability, on the other hand, may be a source of visual interference, which may have negative impact on translation fluency (see research overview in section 2.2.). Other interesting relations to explore are those of the interpreters' speech rate during SiT and disfluency rate in the TT, as well as disfluency rate visà-vis ST characteristics.

Given the limited scope of the pilot study as part of a larger on-going research involving a considerably larger number of participants, including trainee interpreters as well as professionals, within this section of the article only the results pertaining to the main objectives of the study, specified in section 3.1 below, will be presented and discussed.

\subsection{Aims}

The primary aim of the pilot study described in this paper is (1) to identify speech disfluencies recurring in SiT on the basis of a selection of disfluency categories from across the studies on SI described in section 2.1. Other objectives involve (2) measuring the occurrence rate of particular disfluencies identified and (3) detecting any plausible interdependencies of these disfluencies and ST characteristics, including text dominant function.

\footnotetext{
${ }^{4}$ As mentioned in the introductory part, the comfort of this access varies depending on whether the written text is the only input (SiT) or is accompanied by the speaker's oral delivery (with-text-SI). In the latter case, SiT is subject to similar challenges to those of SI.
} 


\subsection{Materials, participants and methods}

This early stage of a broader ongoing project involved 10 professional interpreters sight translating from English (B) into Polish (A) (3 males and 7 females). Interpreting had been the primary area of their professional activity cultivated continuously for no less than four years, a minimum threshold of experience adopted by a translation agency that had helped in recruiting the subjects. The subjects' professional experience ranged between seven and twenty years. They all gave a written consent for their output to be anonymously used for research purposes.

The interpreters participated in the study on-line sight translating three written excerpts of three texts with a different dominant functions (Reiss 1989 in Nord 1997). The order of translating the texts was counterbalanced across the participants. The input texts were: a report on literacy in the USA (302 words, informative function), a review of a book on literacy (293 words, expressive function) and a political speech on literacy (332 words, operative function). As the texts had previously been used for a study on other SiT related aspects, we quote here the rationale behind the text selection method as applied within the original study, which was carried out between 2012 and 2016:

All the passages, 927 words in total, were selected as a result of an Internet engine search for texts whose genres would fit within the text types inspired by Christiane Nord's description of Reiss's typology (Nord 1997). The subjective search was not meant to lead to selecting representative or typical samples of a given genre or function, as (1) the accuracy of such bold labels can be found questionable, (2) the aim was rather to expose the research subjects to text of the varieties they are likely to translate in their professional life under a heading such as a 'report', 'review' or 'speech' however arbitrary they may prove to be, as is often the experience of the translators working in the Polish market. It was, therefore, the overt names the text has been labelled with that were the first selection criterion applied in the search. Certain linguistic markers that tend to be used in each particular genre, further discussed in chapter three, section 3.3 on qualitative analysis of the translation output, 
were considered next, the last criterion being a comparable length of the final set of three STs. (Gorszczyńska 2016: 44)

The report and the speech were edited so as to become uninterrupted passages (e.g. tables were removed from the report and a few paragraphs of the speech were deleted), while no interventions were made into the book description. The length of the passages resulted from pragmatic observations made during a pilot study that had preceded the original research project, which concerned, among others, the fatigue effect on raters involved in the set up with the output of 30 student interpreters, 30 professional interpreters and 30 professional translators.

The interpreters were given two minutes to browse through the set of three texts and asked to immediately proceed to translating them orally one by one, audio recording the entire process. This short initial phase was to enable the participants to get an idea of the general nature and message of each text. In this way, much like in real life setting, they had a chance to produce a more naturally sounding oral output than they might have if they had had enough time to annotate the ST and turn it into a semi-finished written translation to read out. A reservation was made that the interpreters should not resort to any aids and that they should work at their own pace. The subjects were not allowed to introduce any improvements to the recordings of their output after they have completed the sight translation task. Next, all the translations were transcribed, reflecting the division into separate text types. The transcripts were then analysed so as to identify the categories of disfluencies they contained. The table below lists the categories of disfluencies sought for in the present study, which are largely inspired by Gosy's taxonomy (2007). Explicitation was also included to reflect any explicitation shifts other than those that strengthened or created text cohesion (Gumul 2006). As much as such additions and explanations are likely to enhance the comprehensibility of SiT output, they, nevertheless, constitute an intervention into the text that exceeds a rather inconspicuous nature of other translation shifts such as, for instance, reorganizing the 
syntactic structure of a source language sentence. Following Chambers (1997), a fluent speech would be one characterised with uninterrupted natural and proficient flow (emphasis added), while Cecot (2001: 70) lists parenthetical sentences, one of the forms explicitation takes, among disfluencies.

The category of 'silent pauses' (SP) was adopted from Tissi, as was the case with the qualifiers 'vocalized' added to hesitations and 'consonant and vowel' specifying the objects of lengthening (L) (Tissi 2000: 122). The category of vowel and consonant lengthening' is also used by Rennert (2010: 104), whose classification also enriched the one compiled for this study with the category of 'repairs' (RPR) understood as "corrections of errors in pronunciation, grammar, structure, content or style" (Tissi 2000: 114). Additionally, Gósy's category of 'change' (2004) was narrowed down to 'change to a synonym' $(\mathrm{CH})$ to differentiate it from uncertainty rooted 'repairs' (RPR). It should be noted, however, that the nature of revisions such as repairs, repeats, among other types, may also be a manifestation of "the translator's conscious deliberation of text production choices, e.g. translation strategy" rather than being rooted in uncertainty or linguistic or non-linguistic knowledge deficiencies (Shreve, Lacruz and Angelone 2011: 112). The 'grammatical errors' (GE) category has also been adopted from Gósy (2004) but is to be understood as denoting grammatical flaws as a result of disruptions to input processing related to the cognitive effort that accompanies sight translation (Shreve, Lacruz and Angelone 2011: 94).

\section{Table 1}

Types of disfluencies sought for in the present study

\begin{tabular}{|l|}
\hline Types of disfluencies (symbols) to be sought for in SiT \\
\hline Vocalized hesitations (H) \\
\hline Silent pauses (SP) < 2 seconds \\
\hline Fillers (F) \\
\hline Repetitions (RPTN) \\
\hline Repairs (RPR) \\
\hline
\end{tabular}




\begin{tabular}{|l|}
\hline Restarts (RST) \\
\hline Consonant and vowel lengthening (L) \\
\hline In-word pauses (IWP) \\
\hline Freudian slips (FRS) \\
\hline Grammatical errors (GE) \\
\hline Contaminations (CONT) \\
\hline False word activation (FWA) \\
\hline Tip of tongue (TOT) \\
\hline Change to a synonym (CH) \\
\hline Ordering problems (ORD) \\
\hline Spoonerisms (SPN) \\
\hline Explicitations (EXP) \\
\hline
\end{tabular}

\subsection{Results}

\subsubsection{SiT disfluencies in the texts studied}

The Tables 2 to 4 below show the distribution of disfluency categories from the classification presented in Table 1 in relation to the SiTs of the report (Table 2), the review (Table 3) and the political speech (Table 4). The major TT disfluency across all the three text types is that of vocalized hesitations. In the translations of the report, review and political speech, hesitations constituted $40 \%, 41 \%$ and $40 \%$ of the observed disfluencies respectively. A vast majority of them manifested themselves as the Polish equivalents of what Garnham (1985: 206) calls "ums and ahs". The vocalized hesitations reflected in the figures are those that exceeded the cut-off level of 2 seconds adopted in this study as a threshold above which this kind of hesitation marker may be perceived as indicative of translation challenges on the part of the translator. 
Table 2

Distribution of disfluencies in report SiT output

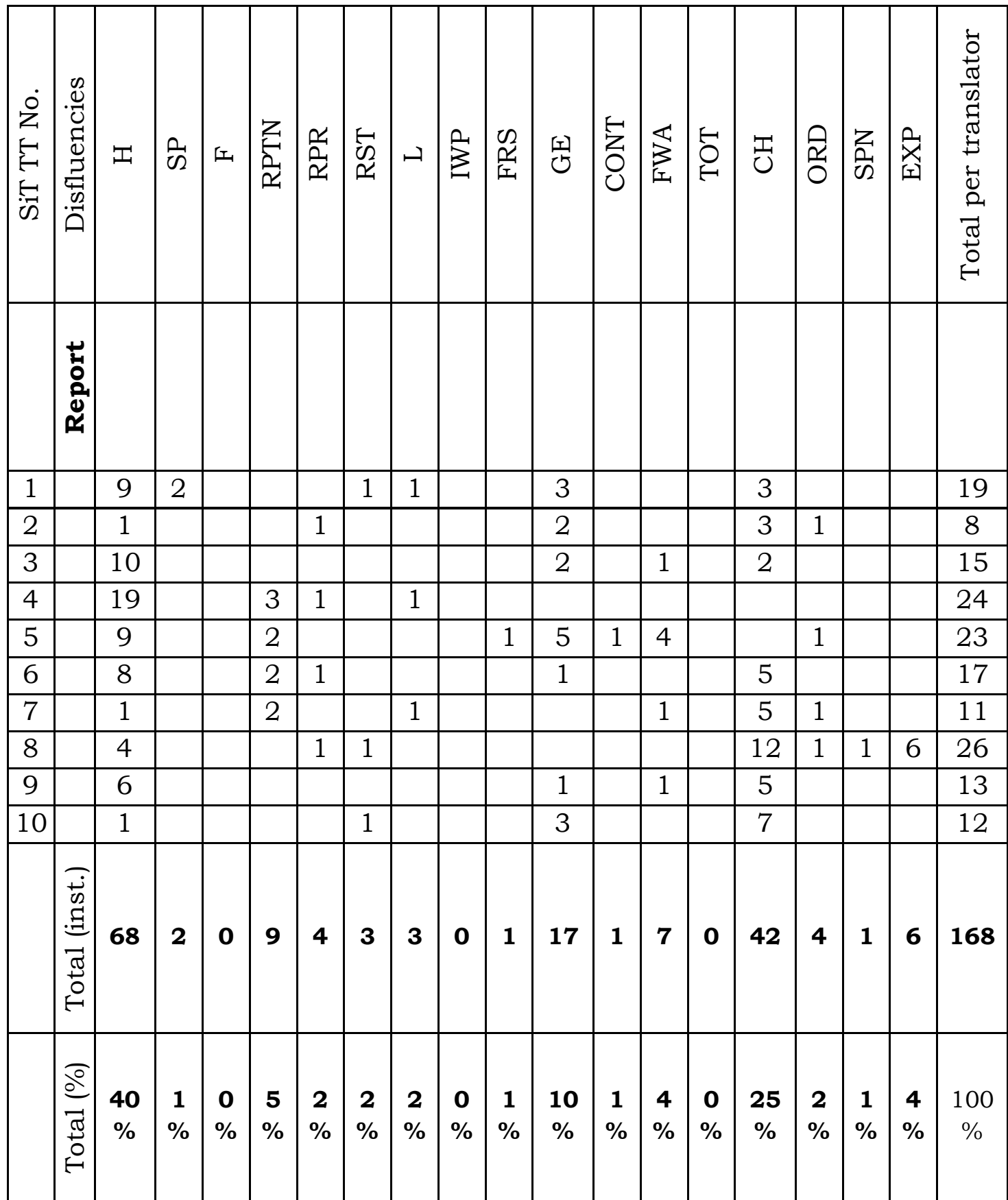


Table 3

Distribution of disfluencies in review SiT output

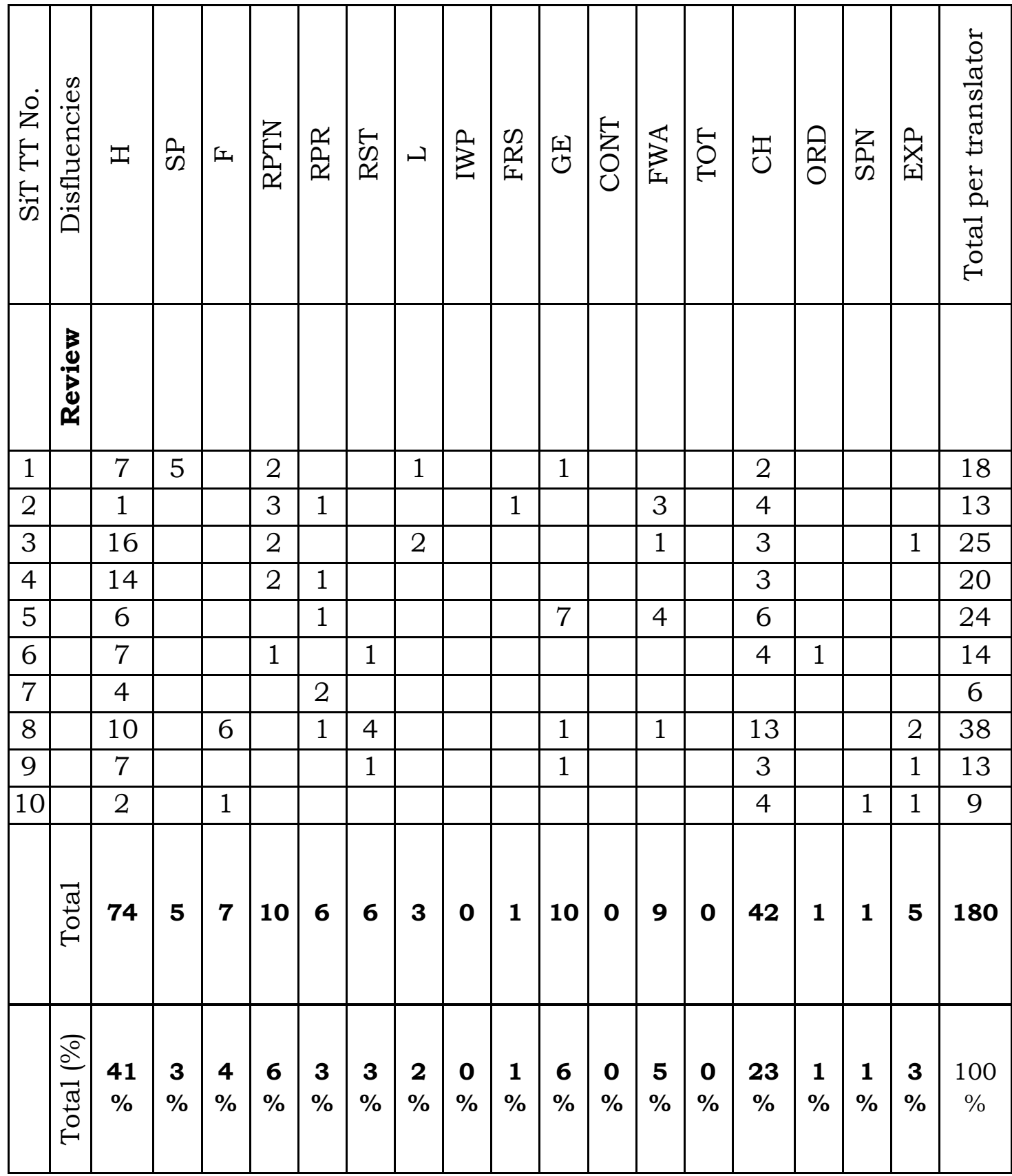


Table 4

Distribution of disfluencies in political speech SiT output

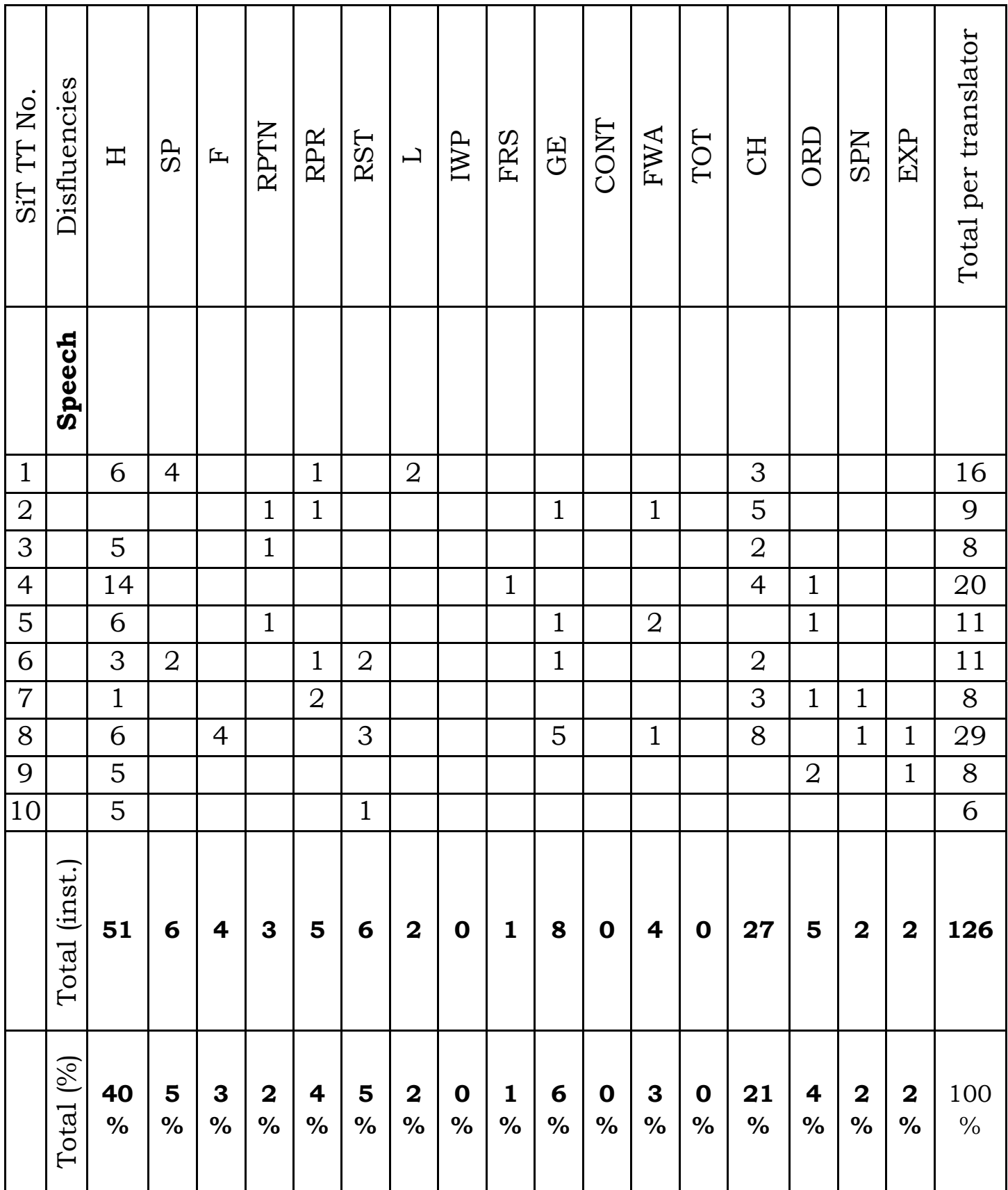

The second most prominent disfluency category, with the occurrence rate of $25 \%, 23 \%$ and $21 \%$ respectively, is change to a synonym, or in Gósy's terms (2007: 93), change. It is to be understood here as the interpreter's decision to withdraw from using the term or phrase and replacing it with another one. The first term used may or may be not be an accuracy error but Gósy 
(2004) places the mechanism of attempting to improve it among error based disfluencies. In this sense change can be exemplified by means of the following passage from one of the TTs:

(1)

ST: Many have absorbed the puritanical message that reading is $[\ldots]$.

TT: Wielu przyjęło $[\mathrm{H}]$ do siebie [FWA] / zinternalizowało [CH] ten [FLL] [H] ów [CH] purytański przekaz, że czytanie to [...]

Back-translation (BT): 'Many have accepted [H] to themselves [FWA] / internalised $[\mathrm{CH}]$ this $[\mathrm{FLL}][\mathrm{H}]$ yon $[\mathrm{CH}]$ puritan message that reading is $[\ldots]$ '.

The verb absorbed in sentence (1), taken from the review excerpt, was first translated as przyjęto, then, after a moment of hesitation, an incorrect sense-changing collocation pattern was activated (do siebie). Immediately afterwards, a synonymous verb was uttered. The rather similar occurrence rate of change across all the three text types may suggest that this disfluency is not text type dependent but rather related to the translation mode. With no noise of oral ST delivery (Bakti 2009: 5) and undisturbed access to the written input, SiT appears to encourage revisions in search for a more suitable word of phrase (Pöchhacker 2004: 19; 2016: 20). In the example analysed here cognate avoidance (zaabsorbowało) is another possible explanation for the word-level repair introduced (Shreve, Lacruz and Angelone 2011: 118).

The third most commonly occurring disfluency type in the SiTs of the report was grammatical errors $(10 \%$ of all the disfluencies detected in this text type), typically consisting in the violation of subject-verb agreement rules in terms of number and/or gender, as in example (2), where, while the subject, per cent, imposes the third person singular form of the verb, the interpreter used the third person plural instead. 
(2)

ST: $65 \%$ of college freshmen read for pleasure for less than [...]

TT: 65 \% osób, które przychodza do college'u czytaja ['read', 3rd person plural] dla przyjemności mniej niż [...]

Grammatical error of the kind illustrated seem likely to recur in SiT of informative texts in particular as their dominating function is habitually supported by grammatical and syntactic patterns that favour placing inanimate nouns such as numbers in the subject position. As we rarely speak statistics, ascribing the right grammatical form to the predicate which follows a number, other numerical value or quantifier does can pose problems to translators who verbally convey their translation.

In the case of the review, the third position was taken by grammatical errors and repetitions (6\% each). The latter are to be understood in this study as the interpreter's repeating an entire word or phrase without introducing any modifications to these units. In the material analysed most repetitions occurred when a given speech unit was delivered twice in a row, which may indicate a speech planning effort or stalling (Rennert 2010: 104). It appears that, contrary to what one might expect, working in the context free of the constraint of time pressure of real life performance and having revision opportunities due to the constant presence of the written input (Pöchhacker 2004: 19; 2016: 20) proved more conductive to repeating than to introducing repairs.

In the translations of the political speech, it is also grammatical errors that ranked third $(7 \%)$, closely followed by restarts (6\%), i.e. interpreters' uttering the first phoneme, syllable or syllables of a word, and then, without finishing it, starting to say the same word either stuttering or stammering or saying the entire word without interruptions. In this sense, restarts can be interpreted as synonymous with what Clark and Clark (1977) call repetitions, allowing them to be incomplete and treating them as representative of hesitations related to incomplete planning. Also Shreve, Lacruz and Angelone refrain from using the term 'restart', "a near synonym for revision or repair, preferring 
to classify all utterance modifications as repairs" (Shreve, Lacruz and Angelone 2011: 99). However, if triangulated with, for instance, retrospective protocol data, making a distinction between particular subtypes of utterance modifications in future studies may shed more light on their underlying causes.

The total number of disfluencies in the report TTs was 168 . The translations of the review were interrupted 180 times, while 126 disfluencies were found in the SiTs of the political speech. The dominating ones having been presented, let us now look at those disfluency categories that either do not appear in the material studied or occur only incidentally (Table 5).

Table 5

Total \% values of disfluencies in the entire SiT output

\begin{tabular}{|l|c|c|}
\hline $\begin{array}{c}\text { Types of disfluencies (symbols) } \\
\text { to be sought for in SiT }\end{array}$ & $\begin{array}{c}\text { No. of } \\
\text { instances }\end{array}$ & $\begin{array}{c}\text { \% of all } \\
\text { instances }\end{array}$ \\
\hline Vocalized hesitations (H) & 193 & 41 \\
\hline Change to a synonym (CH) & 111 & 23 \\
\hline Grammatical errors (GE) & 35 & 7 \\
\hline Repetitions (RPTN) & 22 & 5 \\
\hline False word activation (FWA) & 20 & 4 \\
\hline Repairs (RPR) & 15 & 3 \\
\hline Restarts (RST) & 15 & 3 \\
\hline Silent pauses (SP) < 2 seconds & 13 & 3 \\
\hline Explicitation (EXP) & 13 & 3 \\
\hline Fillers (F) & 11 & 2 \\
\hline Ordering problems (ORD) & 10 & 2 \\
\hline $\begin{array}{l}\text { Consonant and vowel } \\
\text { lengthening (L) }\end{array}$ & 8 & 2 \\
\hline Spoonerisms (SPN) & 4 & 1 \\
\hline Freudian slips (FRS) & 3 & 1 \\
\hline Contaminations (CONT) & 1 & 0 \\
\hline In-word pauses (IWP) & 0 & 0 \\
\hline Tip of tongue (TOT) & 0 & 0 \\
\hline
\end{tabular}


Thus, no pauses within words (IWP) or tips of tongue (TOT) were detected in the entire study material. Additionally, in the renditions of the report, no fillers were spotted, while Freudian slips, ordering issues, contaminations and silent pauses constituted a mere $1 \%$ each of all the disruptions. Similar patterns recur in the review and speech, the difference lying in a greater frequency of silent pauses and fillers in the SiTs of these texts. These instances, which were produced by one or two translators, though statistically insignificant, may indicate that the simpler the ST in terms of style and syntax, which is characteristic of informative text, the more content oriented and careful the translator performing its SiT is likely to be about displaying any hesitation markers and overt additions. The findings concerning a low frequency of unfilled pauses as compared to that of filled pauses seem to corroborate those in Shreve, Lacruz and Angelone (2011: 103), which additionally shows that this performance factor is not necessarily professional experience dependent.

\subsubsection{Frequency of SiT disfluencies versus translators' performance duration}

The speech rate factor in SiT is worth considering in terms of its potential impact on speech disfluencies. As no particular pace is set by the speaker, who is not present in the process, the question of how fast the interpreter processes the textual input and produces its target language version depends on the ST characteristics and the interpreter's abilities. In Tables 6 to 8 quantitative data concerning SiT process duration have been juxtaposed. 
Table 6

Disfluency, translation duration and TT word count in SiTs of the report

\begin{tabular}{|c|c|c|c|}
\hline \multicolumn{4}{|c|}{ Report (302 words) } \\
\hline TT No. & $\begin{array}{c}\text { Number of disfluen- } \\
\text { cies }\end{array}$ & $\begin{array}{c}\text { Performance } \\
\text { time (min:sec) }\end{array}$ & $\begin{array}{c}\text { TT word } \\
\text { count }\end{array}$ \\
\hline 1 & 19 & $3: 40$ & 371 \\
\hline 2 & $\mathbf{8}$ & $\mathbf{3 : 5 6}$ & $\mathbf{3 2 8}$ \\
\hline 3 & 15 & $4: 00$ & 328 \\
\hline 4 & $\mathbf{2 4}$ & $\mathbf{5 : 1 5}$ & $\mathbf{3 8 4}$ \\
\hline 5 & $\mathbf{2 3}$ & $\mathbf{3 : 3 1}$ & $\mathbf{3 2 2}$ \\
\hline 6 & 17 & $3: 56$ & 341 \\
\hline 7 & 11 & $\mathbf{4 : 4 4}$ & 336 \\
\hline 8 & $\mathbf{2 5}$ & $3: 45$ & 362 \\
\hline 9 & 13 & $3: 45$ & 339 \\
\hline 10 & 12 & \multicolumn{3}{|c|}{} \\
\hline
\end{tabular}

When we look at rows 8 and 4 of Table 6 , with the highest number of disfluencies detected in SiTs of the report, we will notice that the disfluencies were found in the outputs whose authors needed more time than the others to complete their translations. The longer it took the subject to translate the texts, the more words their TTs comprise. However, although in row 5 of the same table we see the third highest number of disfluencies in the ten TTs studied, they disfluencies concern the second fastest rendition and the shortest TT. The fewest disfluencies were found in a medium-paced rendition with an average word count (row 2). 
Table 7

Disfluency, translation duration and TT word count in SiTs of the review

\begin{tabular}{|c|c|c|c|}
\hline \multicolumn{4}{|c|}{ Review (293 words) } \\
\hline TT No. & $\begin{array}{c}\text { Number of } \\
\text { disfluencies }\end{array}$ & $\begin{array}{c}\text { Performance } \\
\text { time (min:sec) }\end{array}$ & $\begin{array}{c}\text { TT word } \\
\text { count }\end{array}$ \\
\hline 1 & 18 & $4: 13$ & 405 \\
\hline 2 & 13 & $4: 09$ & 385 \\
\hline 3 & $\mathbf{2 4}$ & $\mathbf{5 : 4 9}$ & $\mathbf{3 3 0}$ \\
\hline 4 & 20 & $5: 22$ & 378 \\
\hline 5 & $\mathbf{2 4}$ & $\mathbf{3 : 4 2}$ & $\mathbf{3 3 1}$ \\
\hline 6 & 14 & $3: 35$ & 306 \\
\hline 7 & $\mathbf{6}$ & $\mathbf{3 : 1 0}$ & $\mathbf{3 0 4}$ \\
\hline 8 & $\mathbf{3 8}$ & $\mathbf{5 : 3 1}$ & $\mathbf{4 2 3}$ \\
\hline 9 & 12 & $3: 24$ & 349 \\
\hline 10 & 9 & $3: 47$ & 357 \\
\hline \multicolumn{4}{|c|}{ Disfluencies in total: 180} \\
\hline
\end{tabular}

In the case of the review, it was the same translator (row 8, Table 7) that generated the largest number of disfluencies (the highest out of all the cases found in the study). Again, their output was very long (second longest in the review part of the study) and contained the highest number of words out of all the review TTs. Interestingly, in row 3 of the same table, with the same number of disfluencies as in row 5, we have the longest speech timewise but, at the same time, the fourth shortest in the set in terms of the word count. The relatively low word count of TTs by the translator who authored the review TT analysed here is consistent across all their outputs. Row 7 shows the lowest number of disfluencies in the shortest text in terms of word count and pace of production, the time and length factor highly consistent in this translator in the entire study, much like in the case of translator 10. This consistency may indicate that the pace at which the professional interpreters translate is related more to their proficiency in SiT and, possibly, their own production style, 
than to the actual challenges posed by the ST. This conjecture, however, requires further confirmation, the more so that it does not fully corroborate the findings of Shreve, Lacruz and Angelone (2011: 118), whose (non-professional) study subjects' slow pace and disfluency effects were interpreted as related "mostly to task characteristics of the sight translation: visual interference, differences between oral source and written STs in terms of syntax, grammar, and register [...]".

\section{Table 8}

Disfluency, translation duration and TT word count in SiTs of the speech

\begin{tabular}{|c|c|c|c|}
\hline \multicolumn{4}{|c|}{ Political speech (332 words) } \\
\hline TT No. & $\begin{array}{c}\text { Number of } \\
\text { disfluencies }\end{array}$ & $\begin{array}{c}\text { Performance } \\
\text { time (min:sec) }\end{array}$ & $\begin{array}{c}\text { TT word } \\
\text { count }\end{array}$ \\
\hline 1 & $\mathbf{1 6}$ & $\mathbf{4 : 0 3}$ & $\mathbf{3 9 0}$ \\
\hline 2 & 9 & $4: 19$ & 379 \\
\hline 3 & 8 & $5: 11$ & 336 \\
\hline 4 & $\mathbf{2 0}$ & $\mathbf{5 : 0 2}$ & $\mathbf{3 8 0}$ \\
\hline 5 & 11 & $3: 20$ & 329 \\
\hline 6 & 11 & $3: 07$ & 295 \\
\hline 7 & 8 & $2: 46$ & 304 \\
\hline 8 & $\mathbf{2 9}$ & $\mathbf{5 : 3 1}$ & $\mathbf{4 0 4}$ \\
\hline 9 & $\mathbf{7}$ & $\mathbf{3 : 1 0}$ & $\mathbf{3 4 0}$ \\
\hline 10 & $\mathbf{6}$ & $\mathbf{3 : 1 0}$ & $\mathbf{3 2 4}$ \\
\hline \multicolumn{4}{|c|}{ Disfluencies in total: 126} \\
\hline
\end{tabular}

In the case of the political speech $\mathrm{SiT}$, it is yet again translator 8 that produced the longest TT over the longest time and with the highest disfluency rate. A look onto the distribution of disfluencies in this translator shows that they hesitate relatively frequently, and add fillers ( 6 in the review, 4 in the speech), unlike the others. What is more, they introduce numerous corrections (12 in the report, 13 in the review, 8 in the speech), outnumbering some of the other translators even twofold, and are 
the only one to resort to explicitation (6 in the report, 2 in the review and 1 in the speech). This translator's output being markedly different from that of the others, let us look into second highest disfluency rate in the table, which is that reflected in row 4 (Table 8). Again, the score matches the production time and relatively high word count, this pattern weakened by the figures in the first row, with medium-duration delivery, the second highest word count and hesitation scores. Moving to the other end of the spectrum and putting aside the out-of-trend incredibly fast rendition of translator 7 , we notice the lowest disfluency score in translator 10 , with the third fastest delivery and second shortest TT. The total cumulative SiT delivery times per text are: 15:31 for the report, 18:42 for the review, and 15:39 for the speech, which, coupled with the highest cumulative disfluency rate for this text type, indicates that the texts with expressive function as the dominating one are likely to put the greatest cognitive strain on the interpreters.

\subsubsection{Triggers of most frequent SiT disfluencies}

A closer look at the target texts reveals certain patterns pertaining to their disfluency triggers. Hesitations in the form of vocalised pauses tend to directly precede the equivalents of polysemic terms and rarely used nouns and verbs, whose first choice equivalents activate strong associations with domains that do not match the general subject matter of the text. This observation can be exemplified by, for instance, eroding in the sense of the deterioration of skills. What is more, hesitations are likely to occur when the interpreter is confronted with a decision about the correct form of the verb in sentences that begin with a collective descriptor such as nearly half, the percentage of, $x \%$, less than one third and millions, particularly when the latter does not immediately precede the verb. Lexical-syntactic pattern of this kind often gives rise to grammatical disfluencies as well.

Scrutinising the manifestations of changes to a synonym, another prominent disfluency category detected, one can notice 
that they are mainly triggered in two contexts. One is when the interpreter notices that a wrong syntactic structure or an incorrect verb grammatical pattern was anticipated and has to withdraw from the initial decision (3a). ${ }^{5}$ Another is lexis based, and involves uttering a correct equivalent of the ST term or a synonym to the term already spoken out as the first choice, often reflex-based (3b).

ST: So we should never forget that what we are doing is vital $[. .$.

TT: A więc nigdy nie powinniśmy zapominać o tym, co, że to, co robimy jest bardzo istotne $[\ldots]$

BT: 'And so we should never forget about what, that what we do is very important $[\ldots]$ '

ST: $[. .$.$] the book explores everything from the invention of silent$ reading $[\ldots]$

TT: książka stanowi wgląd do wszystkiego tego, od wymyślenia, od czasu inwencji, przepraszam, od czasu wymyślenia [...]

BT: The book constitutes insight into all this, from inventing, from the time of invention, sorry, from the time of inventing [...]'

The quantitative analysis of the translators' scores of their sight translations of the three STs seems indicative of a moderately strong interdependence of hesitations, the category of disfluencies prevalent in the TTs of all the ST types, and the pace of delivery. Generally, the slower the delivery, the more disfluencies in the output. The longer the text, the more vocalised disfluencies it is likely to contain, particularly filled pauses and corrections but also explicitations. This approximation, however, should be further verified by analysing more SiT outputs as there are exceptions in the analysed material that go against this tendency (see Table 8, row 3, for instance).

As far as the co-dependence of text characteristics and SiT disfluencies is concerned, the review, despite being the shortest

\footnotetext{
5 Should no correction follow, this kind of disfluency would be categorised as false word activation.
} 
of the three STs, proved to have been most challenging to the subjects, which was reflected in its total cumulative delivery time (18:42) compared to the total number of disfluencies (180). The major disfluency trigger in this text seems to be the one of sophisticated lexis, convoluted syntax and rhetorical devices that do not match the conventions applying in Polish. The difference in total cumulative delivery time between the report and the political speech was merely 8 seconds, with the report having been delivered in a shorter time. However, despite both texts having a similar word count, with the speech containing 30 words more, the proportion of disfluencies was 126 to 168 , the higher number pertaining to the shorter text of the report. This observation, backed up with the qualitative analysis of source and target text features, can indicate that the greater degree of orality of the speech text made it easier to translate than the report with its syntax more typical of written language, challenging verbs describing trends and scarce cohesion markers.

\section{Conclusions}

The study revealed that not all the categories of disfluencies adapted from the SI disfluency taxonomies discussed in the Introduction to the present paper and presented in Tables 1 and 5 apply to the SiT output analysed. From among those that clearly do, an impressive value of $41 \%$ was classified as vocalized hesitations, followed by changes to a synonym (23\%). The third top category, grammatical errors (7\%), opens a list of 15 re-maining categories with a one digit percentage frequency. At the bottom of the list we find the disfluencies that did not disrupt the recorded performance. These are contaminations, inword pauses and tip-of-tongue disfluencies. In between the topand bottom-of-the-list categories, there are disfluencies described in the analysis, whose occurrence, in the case of professional interpreters, may indicate the applied solution evaluation in progress (Angelone 2010) rather than actual syntactic or lexical production problems aggravated by the visual interference of the written source or the novelty of the SiT task (Shreve, 
Lacruz and Angelone 2011). In professionals, this interference is perhaps strongest where grammatical errors and ordering problems emerge. Thus repetitions, false word activation and fillers may be triggered by the application of the least effort principle, i.e. uttering the first solution that offers itself even if this is not the optimum one. This, done intentionally or unintentionally, is su-pposed to ensure a continuous flow of speech, with as few lengthy silent pauses as possible. Repairs, restarts and explicitations may be used as fixing strategies that set in when the applied solution evaluation proved negative. However, although some evidence was found that seems to support these conjectures, a more careful analysis of particular instances of these disfluencies is advisable, preferably involving a greater number of professional interpreters or translators as participants, plus triangulation with, for example, eye-tracking metrics and retrospective protocols.

Dominating text functions reflected in textual features of the STs appear to be only moderately related to range of the top scoring disfluencies detected in the study. These differences, concerning frequency figures for vocalized hesitations, changes to a synonym and grammatical errors are more apparent in the frequency of their occurrence than in the presence or absence of particular disfluency types in the target texts. Major disfluency triggers in the review, the text with the highest number of SiT disfluencies, seem to be sophisticated lexis, convoluted syntax and rhetorical devices that do not match the conventions applying in Polish. Repetitions and false word activation point at the interpreters' having struggled with these features of the expressive text. The renditions of the report displayed instances of the same right-out-of-the-top-three types of disfluencies, which were triggered by syntax more typical of written language, challenging verbs and phrases describing trends and scarce cohesion markers. Explicitations did rank next to repetitions and false words activated but came from a single translator only. As regards the speech, oralised as the text was in the appellative parts, it contained simpler sentences (hence fewer grammatical errors were found than in the remaining texts) but also a few 
fixed phrases. In this case, the interpreters appear to have been more careful about their lexical choices and speech planning, which is reflected in the relatively high frequency of restarts and silent pauses instead of false word activation left without any modification.

In order for SiT to be able to draw from the analytical and methodological legacy of Interpreting Studies and interpreter training, with the perspective of speech disfluencies as a starting point, further studies should be encouraged. They could aim to, for example, discover mechanisms that stimulate disfluencies and adjust interpreter training methods that would facilitate their prevention. Naturally, study replications across different language pairs would have to be performed to gain further insight into the degree of universality of the findings.

\section{References}

Angelelli, Claudia V. (1999). "The role of reading in sight translation". The ATA Chronicle (Translation Journal of the American Association of Translators) 28/5: 27-30.

Angelone, Eric (2010). "Uncertainty, uncertainty management and metacognitive problem solving in the translation task". In: Eric Angelone, Gregory M. Shreve (eds.). Translation and Cognition. Amsterdam - Philadelphia: John Benjamins, 17-40.

Bakti, Mária (2009). "Speech disfluencies in simultaneous interpreting”. In: Dries De Crom (ed.). (Trans)formation of Identities: Selected Papers of the CETRA Research Seminar in Translation Studies 2008. Leuven: KU Leuven Centre for Translation Studies, 1-18.

Bakti, Mária (2017). "Explicitation in sight-translating into Hungarian texts”. In: Andrzej Łyda, Katarzyna Holewik (eds.). Interdisciplinary Encounters: Dimensions of Interpreting Studies. Katowice: Wydawnictwo Uniwersytetu Śląskiego: 136-148.

Cecot, Michaela (2001). "Pauses in simultaneous interpretation: A contrastive analysis of professional interpreters' performances". The Interpreters' Newsletter 11: 63-85.

Chambers, Francine (1997). "What do we mean by fluency?" System 25/4: 535-544.

Christodoulides, George, Cédric Lenglet (2014). "Prosodic correlates of 
perceived quality and fluency in simultaneous interpreting". In: Nick Campbell, Dafydd Gibbon, Daniel Hirst (eds.). Proceedings of 7th International Conference on Speech Prosody 2014, 20-23 May 2014. Dublin: Trinity College Dublin, 1002-1006.

Clark H. Herbert, Eve V. Clark (1977). Psychology and Language: An Introduction to Psycholinguistics. New York: Harcourt Brace Jovanovich.

Collados Aís, Ángela, Olalla Garcia Beccerra, Esperanza Macarena Pradas Macias, Elisabeth Stévaux (2007). La evaluación de la calidad en interpretación simultánea: parámetros de incidencia. Granada: Comares.

García Becerra, Olalla. (2007). "La incidencia de las primeras impresiones en laevaluación de la calidad de la interpretación. Estudio piloto". In: María Manuela Fernández Sánchez, Ricardo Muñoz Martín (eds.). Aproximaciones cognitivas al estudio de la traducción y lainterpretación. Granada: Comares, 302-326.

Garnham, Alan (1985). Psycholingusitics. Central Topics. London: Methuen.

Gorszczyńska, Paula (2016). Recorded Sight Translation Revisited: The Benefits of Technology-Assisted "Dictated" Translation. Gdańsk: Wydawnictwo Uniwersytetu Gdańskiego.

Gósy, Mária (2004). "A spontán magyar beszéd megakadásainak hallás alapú győjteménye”. In: Mária Gósy (ed.). Beszédkutatás 2004. "Nyelvbotlás”- korpusz, tanulmányoki. Budapest: MTA Nyelvtudományi Intézet, Kempelen Farkas Beszédkutató Laboratórium, 618.

Gósy, Mária (2007). "Disfluencies and Self-monitoring". Govor 24: 91110.

Götz, Sandra (2013). Fluency in Native and Non-native English Speech. Amsterdam - Philadelphia: John Benjamins.

Gumul, Ewa (2006). "Explicitation in simultaneous interpreting: A strategy or a by-product of language mediation?". Across Languages and Cultures 7/2: 171-190.

Lambert, Sylvie (2004). "Shared attention during sight translation, sight interpretation and simultaneous interpretation". Meta 41/1: 75-83.

Magno Caldognetto, Emanuela, Enrica De Zordi, Loredana Corrà (1982). "Il ruolo delle pause nella produzione della parola". Il Valsalva - Bollettino della Società Italiana di Audiologia e Foniatria 5: 12-21.

Mikkelson, Holly (1995). The Interpreter's Edge. San Diego: ACEBO. 
Nord, Christiane (1997). Translation as a Purposeful Activity. Manchester: St Jerome.

Parkin, Christina (2012). Stegreifübersetzen. Überlegungen zu einer Grenzform der Translation am Beispiel des Sprachenpaares Franzosisch-Deutsch. Frankfurt am Main: Peter Lang.

Pöchhacker, Franz (2016). Introducing Interpreting Studies. London New York: Routledge.

Pradas Macias, Esperanza Macarena (2006). "Probing quality criteria in simultaneous interpreting: The role of silent pauses in fluency". Interpreting 8/1: 25-43.

Pradas Macías, Esperanza Macarena (2007). "La incidencia del parámetro fluidez". In: Angela Collados Aís, Olalla Garcia Beccerra, Esperanza Macarena Pradas Macías, Elisabeth Stévaux (eds.). La evaluación de la calidad en interpretación simultánea: parámetros de incidencia. Granada: Comares, 53-70.

Reinart, Sylvia (2014). Lost in Translation (Criticism)? Auf dem Weg zu einer konstruktiven Übersetzungskritik. Berlin: Frank \& Timme.

Reiss, Katharina (1989). "Text types, translation types and translation assessment”. In: Andrew Chesterman (ed.). Readings in Translation Theory. Helsinki: Finn Lectura, 105-115.

Rennert, Sylvi (2010). "The impact of fluency on the subjective assessment of interpreting quality”. The Interpreters' Newsletter 15: 101115.

Shreve, Gregory M., Isabel Lacruz, Erik Angelone (2010). "Cognitive effort, syntactic disruption, and visual interference in a sight translation task". In: Eric Angelone, Gregory M. Shreve (eds.). Translation and Cognition. Amsterdam - Philadelphia: John Benjamins, 63-84. Shreve, Gregory M., Isabel Lacruz, Erik Angelone (2011). "Sight translation and speech disfluency: Performance analysis as a window to cognitive translation processes". In: Cecilia Alvstad, Adelina Hild, Elisabet Tiselius (eds.). Methods and Strategies of Process Research. Amsterdam - Philadelphia: John Benjamins, 121-146.

Tissi, Beneditta (2000). "Silent pauses and disfluencies in simulta-neous interpretation: A descriptive analysis”. The Interpreters' Newsletter 10: 103-127. 
Paula Gorszczyńska

ORCID iD: 0000-0002-3125-5116

University of Gdańsk

Institute of English and American Studies

Wita Stwosza 51

80-308 Gdańsk

Poland

paula.gorszczynska@ug.edu.p1 